J. Dairy Sci. 95:5527-5535

http://dx.doi.org/10.3168/jds.2011-4933

(C) American Dairy Science Association ${ }^{\circledR}, 2012$.

\title{
Impact of curd milling on the chemical, functional, and rheological properties of starter-free Queso Fresco ${ }^{1,2}$
}

\author{
D. L. Van Hekken, ${ }^{3}$ M. H. Tunick, L. N. Leggett, and P. M. Tomasula \\ Dairy \& Functional Foods Research Unit, Eastern Regional Research Center, Agricultural Research Service (ARS), \\ United States Department of Agriculture (USDA), Wyndmoor, PA 19038
}

\begin{abstract}
The manufacture of Queso Fresco (QF), a highmoisture fresh Mexican cheese that is popular in the Americas, varies from country to country, with many manufacturers milling the curd before forming the cheese block to disrupt the protein matrix and ensure the crumbly nature of the QF. Because this traditional milling step does take time and may be an unnecessary point of microbial contamination, this study was undertaken to determine whether the curd-milling step could be omitted without altering the chemical, functional, and textural properties of the QF. Starter culture-free, rennet-set QF was prepared from pasteurized, homogenized milk. Curds were cooked at $39^{\circ} \mathrm{C}$ for $30 \mathrm{~min}$, wet salted at $1.45 \mathrm{~g}$ of $\mathrm{NaCl} / 100 \mathrm{~g}$ of milk, chilled, and divided into 4 portions. Curds were not milled or were subjected to coarse, medium, or fine milling and handpacked into molds. After $12 \mathrm{~h}$ at $4^{\circ} \mathrm{C}$, the cheese was divided, vacuum packaged, and stored at $4^{\circ} \mathrm{C}$ for up to 8 wk. Fresh QF contained $57.3 \pm 1.2 \%$ moisture, 20.9 $\pm 0.8 \%$ fat, $16.0 \pm 1.3 \%$ protein, $2.61 \pm 0.15 \%$ lactose, and $2.25 \pm 0.22 \%$ salt and had a pH of $6.36 \pm 0.03 \%$. Moisture decreased over the $8 \mathrm{wk}$ of storage, whereas the fat level tended to increase. All cheeses lost 1.3 to $1.7 \%$ of their weight in whey during the first week after manufacture, and the weight gradually increased to $2.1 \%$ (nonmilled) to $3.2 \%$ (milled) by wk 8 . Milling did result in QF that were softer, less chewy, and less rigid and with lower viscoelastic properties than nonmilled cheeses. Sensory panelists differentiate the finely milled $\mathrm{QF}$ from the other treatments, but they detected no significant differences among the nonmilled, coarsely milled, and medium-milled QF. Milling of the curd did not affect the ability of Listeria monocytogenes to grow on the cheese surface. Results from this study indicate

\footnotetext{
Received September 14, 2011.

Accepted May 29, 2012.

${ }^{1}$ USDA is an equal opportunity provider and employer.

${ }^{2}$ Mention of trade names or commercial products in this publication

${ }^{3}$ Corresponding author: diane.vanhekken@ars.usda.gov
} is solely for providing specific information and does not imply recommendation or endorsement by the USDA.
\end{abstract}

that the milling step, which lengthens the manufacturing time, does increase wheying off during storage and results in a more fragile protein matrix. Cheese manufacturers can use this information to produce a $\mathrm{QF}$ that meets the demands of their customers.

Key words: cheese, Queso Fresco, functionality, quality trait

\section{INTRODUCTION}

Of the 215 million pounds of Hispanic-style cheese made in the United States last year (NASS, 2011), Queso Fresco (QF) is one of the most popular of the fresh cheeses. It is typically described as a bright white, high-moisture, rennet-set cheese that typically crumbles very well, does not melt, and has a mild fresh-milk flavor with a distinct salty note. Many countries and regions in the Americas make QF using slight differences in manufacturing protocols and ingredients; therefore, the composition has been reported to range from 46 to $57 \%$ moisture, 18 to $29 \%$ fat, 17 to $21 \%$ protein, and 1 to $3 \%$ salt (Van Hekken and Farkye, 2003).

Traditionally manufactured from raw milk, which supplied ample microflora, QF was made without adding starter cultures and the curd was commonly finely milled (Higuera-Ciapara, 1986) or crumbled before packing into molds (Clark et al., 2001; Escobar et al., 2011) to enhance the crumbliness of the cheese. The average QF available in the United States has $\mathrm{pH}>6.1$ (Van Hekken and Farkye, 2003), which, when coupled with the high moisture content, has greater food safety risks (Genigeorgis et al., 1991). Although, in the United States, QF must be made from pasteurized milk (CFR, 2011), Hispanic-style cheeses are still plagued by postmanufacturing contamination and have been linked to foodborne pathogen outbreaks (Linnan et al., 1988; CDC, 2001; MacDonald et al., 2005).

Other studies have examined the quality traits of QF. This bright white cheese will brown slightly when baked at $130^{\circ} \mathrm{C}$ for $30 \mathrm{~min}$ and, if made with homogenized full-fat milk, will soften but not melt and flow when heated at $232^{\circ} \mathrm{C}$ for 5 min (Tunick et al., 2012). Queso Fresco has a weak protein matrix that easily fails 
or crumbles when stressed (Hwang and Gunasekaran, 2001; Guo et al., 2011; Tunick et al., 2012). Sensory traits of QF include a mild fresh-milk flavor with a distinct salty note (Path, 1991). Clark et al. (2001) reported that US consumers on the West Coast preferred QF containing 1.4 to $2.4 \%$ salt and with a $\mathrm{pH}$ of 5.4 to 6.1. Guo et al. (2011) found that QF containing 1.5 to $2.5 \%$ salt and $\mathrm{pH} 6.3$ had similar stable functional and rheological properties over an 8-wk refrigeration storage period, whereas $\mathrm{QF}$ containing $<1.5 \%$ salt began to have quality problems over time as spoilage bacterial levels increased (Guo et al., 2012). In our laboratory, we characterized the quality traits of a starter-free rennet-set QF made using pasteurized, homogenized milk (Tunick et al., 2012) for use in a study to evaluate the growth of Listeria monocytogenes $(\boldsymbol{L m})$ within and on the surface of QF (Leggett et al., 2012). As part of this study, traditional manufacturing steps were carefully evaluated for their risk factors, and the curd-milling step was targeted as a potential point at which pathogens are introduced into the cheese. The present study was undertaken to determine whether the curd-milling step could be omitted without altering the chemical, functional, and textural properties of QF.

\section{MATERIALS AND METHODS}

\section{Cheesemaking}

Four batches of QF were made using a modification of the procedure described by Guo et al. (2011). The basic steps are shown in Figure 1; 180 L of cheesemilk yielded 15 to $16 \% \mathrm{QF}$. The modification to the procedure included wet salting the curd in the cheese vat, based on common commercial QF manufacturing protocols (N. Y. Farkye, California Polytechnic State University, San Luis Obispo, personal communication). After the cooking step, $90 \mathrm{~kg}$ of whey was drained and salt ( $14.5 \mathrm{~g}$ of salt $/ \mathrm{kg}$ of cheesemilk) was added in 3 applications, with $10 \mathrm{~min}$ of mixing between applications. After the curds were chilled to core temperatures below $21^{\circ} \mathrm{C}$, they were divided into 4 portions. The milling treatments included no milling (control), passing through the milling unit without blades using the screw auger only (coarse milling; Figure 2a), milled using a blade with five 14-mm-diameter holes (Bosch universal 6610UC/01 FD, Robert Bosch Hausgerate GmbH, Dillingen, Germany; medium milling; Figure 2b), and milled using a blade with eighteen 8-mm-diameter holes (Waring Pro MG-800, Waring, East Windsor, NJ; fine milling; Figure 2c). Curds from each treatment were hand-packed into separate $10 \times 20 \times 25 \mathrm{~cm}^{3}$ molds and stored at $4^{\circ} \mathrm{C}$ for $12 \mathrm{~h}$. After removal of the cheese from the mold, approximately one-fourth of the cheese was used for the wheying-off study, another one-fourth of the cheese was relegated to either the microbiology assays (2 batches of cheese) or to sensory evaluations ( 2 batches of cheese), and the remaining cheese was divided into three $6.5 \times 10 \times 12 \mathrm{~cm}^{3}$ blocks, vacuum packed, and stored at $4^{\circ} \mathrm{C}$. After 1,4 , and 8 wk of storage, one of the blocks was removed and divided into smaller pieces for various quality trait assays.

\section{Composition and $\mathrm{pH}$}

The composition of QF was determined after 1, 4, and $8 \mathrm{wk}$ of storage at $4^{\circ} \mathrm{C}$. Moisture was determined in triplicate using the forced-air oven method (method 948.12; AOAC International, 2000). Total fat levels were measured in duplicate using a modification of the Babcock procedure (Kosikowski and Mistry, 1997). Total nitrogen was measured in triplicate using a Flash EA1112 nitrogen analyzer (Thermo Fisher Scientific, Lakewood, NJ), and protein was calculated by multiply the nitrogen content by 6.38 . Lactose was determined in triplicate on warm water filtrates using a lactose analyzer (Application Note No. 320; model YSI 2700 Select, YSI US, Yellow Springs, OH). Ash content was obtained in duplicate using the furnace method (Lindberg Furnace, Watertown, WI; method 945.46; AOAC International, 2000). Salt was determined in triplicate using high-range chloride titrators (Hach Co., Loveland, $\mathrm{CO})$. Salt in moisture was defined as (\% salt $/ \%$ moisture) $\times 100$, and fat in DM was defined as (\% fat $/ \%$ $\mathrm{TS}) \times 100$. The $\mathrm{pH}$ was measured at 6 points within the cheese block by using a point tip probe (model 611; Orion Research Corp., Cambridge, MA).

\section{Functional Properties}

Wheying Off. On d 1, the QF from each milling treatment was cut into multiple $4.0 \times 6.3 \times 6.3 \mathrm{~cm}^{3}$ blocks weighing between 150 and $200 \mathrm{~g}$, vacuum packaged, and stored at $4^{\circ} \mathrm{C}$. At wk 0, 1, 2, 3, 4, 6, and 8 , three random packages from each treatment were removed from storage and the weight of free whey that had accumulated in the package was obtained. Ten grams from each sample was then centrifuged at 10,000 $\times g$ for 30 min at $15^{\circ} \mathrm{C}$ and the weights of the supernatant (expressible serum) were obtained.

Color and Melt. Color and melt properties were obtaining using the procedure described by Olson et al. (2007) as modified by Guo et al. (2011) on samples stored at $4^{\circ} \mathrm{C}$ for 1,4 , and 8 wk. Briefly, 6 disks $(5 \mathrm{~mm}$ thick, $38 \mathrm{~mm}$ in diameter) were prepared from each sample, and initial color values for $\mathrm{L}^{*}$ (white, 100, to black, 0), a* (red, positive, to green, negative), and $\mathrm{b}^{*}$ (yellow, positive, to blue, negative) were measured using 


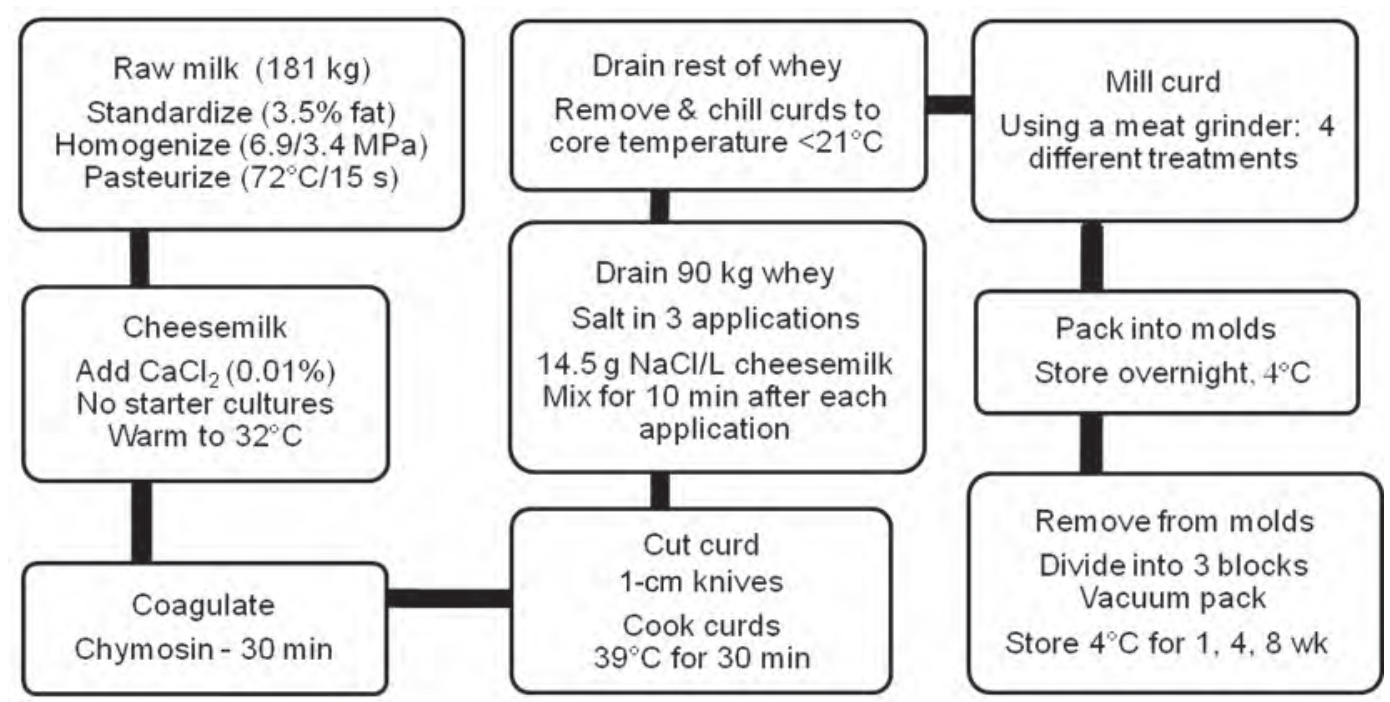

Figure 1. Flow diagram of the procedure used in this study to manufacture Queso Fresco.

a Hunter Lab ColorQuest XE colorimetric spectrophotometer (Hunter Associates Laboratory, Reston, VA). Four measurements were taken for each disk. Three disks were heated at $232^{\circ} \mathrm{C}$ for 5 min or at $130^{\circ} \mathrm{C}$ for 30 min. After cooling, color measurements were collected and used to calculate total color change (equation 1; Hunter, 1975):

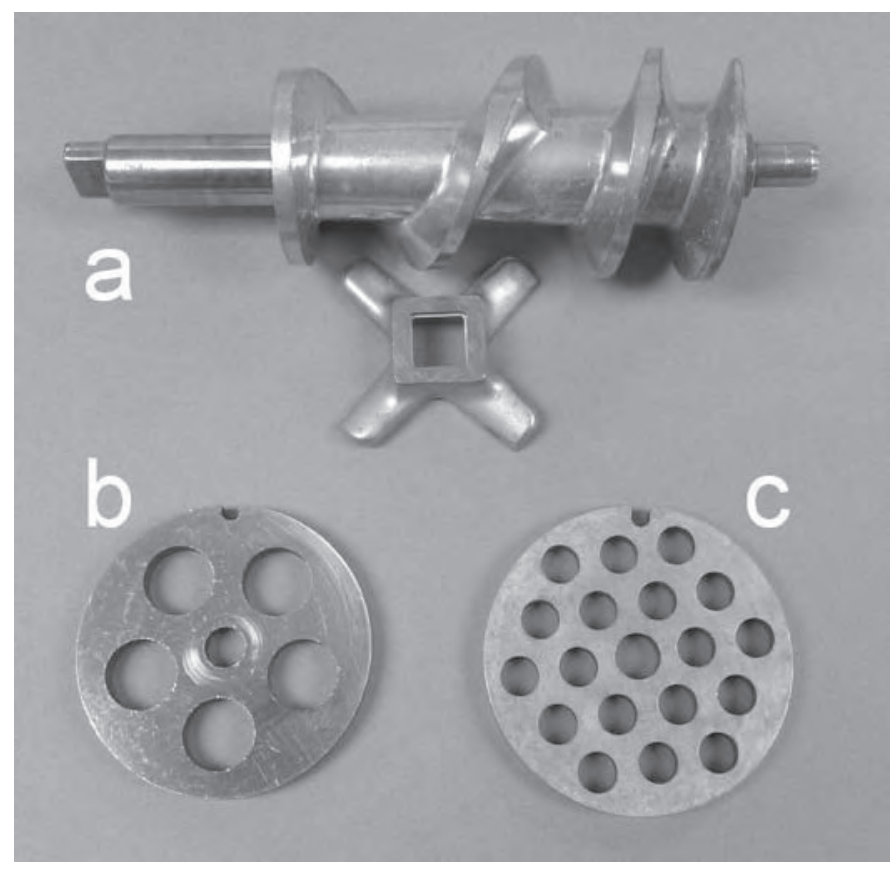

Figure 2. Different blades used to mill the curd: a) coarse milling, no blade, only screw auger; b) medium milling, blade with 5 large holes; and c) fine milling, blade with 18 small holes. total color change $=\left(\Delta \mathrm{L}^{*^{2}}+\Delta \mathrm{a}^{*^{2}}+\Delta \mathrm{b}^{*^{2}}\right)^{1 / 2} \cdot[1]$

Meltability was determined in triplicate using the Schreiber melt test as described by Kosikowski and Mistry (1997). Briefly, disk diameters were measured at 6 points after heating at $232^{\circ} \mathrm{C}$ for $5 \mathrm{~min}$. A value of 1.0 indicated no change in disk diameter, indicating that the sample did not melt or flow upon heating.

\section{Microstructure}

Samples of fresh and 8-wk-old QF were prepared for scanning electron microscopy as described by Tunick et al. (2008). Briefly, 1.0- $\mathrm{cm}^{3}$ samples were fixed in a $2.5 \%$ glutaraldehyde- $0.1 M$ imidazole solution, diced into $0.2-\mathrm{cm}^{3}$ cubes, dehydrated through a series of ethanol washes, frozen and fractured in liquid nitrogen, critical point dried, mounted on stubs, and sputter-coated with gold. Images were obtained using a Quanta 200 field emission scanning electron microscope (FEI Co., Hillsboro, OR).

\section{Rheology}

At 1, 4, and 8 wk after manufacture, one large block of cheese from each treatment was removed from $4^{\circ} \mathrm{C}$ storage and divided for testing. Samples for rheological analyses were warmed to room temperature $\left(22^{\circ} \mathrm{C}\right)$ for $1 \mathrm{~h}$ prior to testing.

Texture Profile Analysis. Textural properties were obtained as described by Van Hekken et al. (2007). Four cylindrical plugs from each treatment sample was compressed by $75 \%$ twice in a Universal Testing Machine 
(Model SM-25-155; Material Testing Products Systems Corp., Eden Prairie, MN) using a crosshead speed of $100 \mathrm{~mm} / \mathrm{min}$. Hardness, cohesiveness, and springiness values were obtained from time-force curves, and values were multiplied together to calculate the chewiness of the samples.

Torsion Analysis. Fracture properties were obtained as described by (Van Hekken et al., 2007). Capstan-shaped samples $(1.0 \mathrm{~cm}$ in diameter at the center $)$ were milled from 4 plugs taken from each treatment sample, placed in a Gelometer (Gel Consultants Inc., Raleigh, NC), and twisted at $2.5 \mathrm{rpm}$ until fracture. Shear stress and strain at the point of fracture were measured from strain-time curves, and shear stress was divided by shear strain to obtain shear rigidity at the point of failure.

Small Amplitude Oscillatory Shear Analysis. Viscoelastic properties were obtained as described by Van Hekken et al. (2007). Triplicate discs (diameter, 25 $\mathrm{mm}$; height, 4 to $5 \mathrm{~mm}$ ) were obtained from each treatment sample, glued to parallel plates, and placed in a Dynamic Analyzer (AR-2000; TA Instruments, New Castle, DE). Viscoelastic properties (elastic modulus and viscous modulus) were obtained from frequency sweeps conducted at a strain of $0.8 \%$.

\section{Sensory Evaluation}

Portions from 2 batches of cheese were used to conduct difference testing. Samples from each treatment were aseptically removed from the center of the cheese block and sent to a licensed laboratory to confirm the microbial safety of the cheese before presentation to panelists. Eight days after manufacture, cheeses were cut into $2.5 \mathrm{~cm}^{3}$ cubes, placed in coded 3 -oz. capped cups, and refrigerated at $4{ }^{\circ} \mathrm{C}$. All cheeses were warmed at room temperature $30 \mathrm{~min}$ before presentation to inhouse panelists $(\mathrm{n}=23)$. Triangle tests were conducted to determine differences among the treatments. Each panelist received 4 sets of cheese with distilled water and unsalted crackers to clean their palates between samples.

\section{Microbiological Properties}

The growth curve of $L m$ on the surface of QF slices was determined as described by Leggett et al. (2012). Briefly, on d 1, QF from each milling treatment was cut into multiple slices, $5.0 \times 10 \times 1.2 \mathrm{~cm}$, inoculated on both sides with a cocktail containing 5 dairy-based rifampicin (rif)-resistant $L m$, and vacuum packed for storage at $4^{\circ} \mathrm{C}$. At d $0,5,14$, and 20 , two slices from each treatment were removed from storage and homogenized separately in $50 \mathrm{~mL}$ of sterile $0.1 \%$ peptone wa- ter, serial diluted, and plated on duplicate $\mathrm{MOX}^{\text {rif }}$ agar plates (rifampicin was added to prevent overgrowth of $L m$ by other contaminating bacteria). After $48 \mathrm{~h}$ at $37^{\circ} \mathrm{C}$, colonies were counted and presented as colonyforming units per gram of sample.

\section{Statistics}

Results from assays measuring composition, $\mathrm{Lm}$ growth, wheying off, and rheological properties were analyzed using milling treatment and storage time as the main effects (SAS version 9.2 for Windows; SAS Institute Inc., Cary, NC). Significant differences $(P<$ 0.05 ) among means were compared using the Bonferroni correction within the PROC MIXED program. Sensory triangle scores were evaluated using the critical number of correct responses in the triangle test (Meilgaard et al., 1999).

\section{RESULTS AND DISCUSSION}

\section{Composition}

The composition of fresh QF (Table 1) was typical of a soft, full-fat cheese, with $57.3 \pm 1.2 \%$ moisture, 20.9 $\pm 0.8 \%$ fat, $16.0 \pm 1.3 \%$ protein, and $2.25 \pm 0.22 \%$ salt. The lactose level, $2.61 \pm 0.15 \%$, and $\mathrm{pH}, 6.36 \pm$ 0.03 , reflected the lack of lactose-fermenting bacteria in the cheese. Moisture was the only component that decreased significantly $(P<0.05)$ over the 8 wk of the study, and this was related to the free whey that accumulated in the package. As moisture was lost from the cheese matrix, the levels of fat tended to be higher but the increase was not statistically significant. Salt concentrations and the salt-in-moisture values also tended to be lower after $8 \mathrm{wk}$ of aging. Loss of whey from the QF over time would remove some salt from the cheese matrix but it is unclear if it would account for the $0.2 \%$ salt reduction. The presence of free whey in packaging is a continuing concern for QF producers, especially because storage temperature abuse can enhance wheying off (Tunick et al., 2012). See the Functional Properties section for more discussion on the loss of whey from $\mathrm{QF}$.

Composition of the QF was within the ranges reported for commercial QF in the United States (Hwang and Gunasekaran, 2001; Van Hekken and Farkye, 2003) and for QF previously made in our facilities (Guo et al., 2011, 2012; Leggett et al., 2012; Tunick et al., 2012). Our QF was lower than the 61.7 to $67.5 \%$ moisture and higher than the 14.8 to $15.6 \%$ fat reported for the artisan Mexican QF manufactured by Torres-Llanez et al. (2006) using raw milk, dry salting, and slight pressing. Our QF was similar in moisture, fat, and protein 
levels reported for QF made with high-pressure-treated milk, starter cultures, and light pressing (Sandra et al., 2004).

\section{Functional Properties}

Wheying Off. Within the first week of storage, all the cheeses lost 1.3 to $1.9 \%$ of their weight as free whey that accumulated in the packaging (Figure 3). Free whey is the liquid portion that pools between curd particles and is lost as the fresh cheese undergoes the last stages of syneresis. Over the next $7 \mathrm{wk}$ as the matrix stabilized, the amount of free whey in the packaging slowly increased, with the milled samples having lost 3.1 to $3.2 \%$ of their weight as free whey. Although not significantly different from the milled treatments $(P>$ 0.05 ), the nonmilled control had the least amount of free whey, 2.16\%. Manufacturers selling QF in smaller portions, usually less than $0.5 \mathrm{~kg}$, will typically include a pressing step to remove some of the free whey from the cheese before packaging, which results in drier $\mathrm{QF}$, around $50 \%$ moisture. Manufacturers selling the larger wheels destined for food service and delicatessens typically do not press these cheeses but may have more complaints of wheying off. Tunick et al. (2012) reported that $\mathrm{QF}$ stored at $10^{\circ} \mathrm{C}$ had higher wheying-off losses than cheese stored at $4^{\circ} \mathrm{C}$, which would be the circumstances in delicatessen services, where the cheese is removed to room temperature for slicing throughout the day. Quick chilling of the curd after manufacture and vacuum packaging of the cheeses have long been used to control the loss of whey in high-moisture Hispanicstyle cheeses (Weigold, 1958).

Upon light centrifugation, the amount of expressible whey varied with the milling treatment (Figure 3) during the first 2 wk after manufacture. The control sample and the coarsely milled sample, which would have the least amount of disruption to the protein matrix, had the highest amounts of expressible whey, whereas the medium-milled and finely milled QF, which would have more surface area exposed to moisture, had less $(P<0.05)$ expressible serum. The amount of expressible serum decreased over the first 2 wk, probably as the protein in the matrix rehydrated and absorbed the moisture. At wk 3, all treatments had the same amount of expressible serum whey, which then continued to decrease through the rest of the study.

Homogenization of cheesemilk is noted to result in a finer protein matrix, which does not fuse together and retains more moisture and fat (Scott, 1986). In the case of QF, the milling step would take this delicate matrix and break it further into small masses (Figure $2 b$ ). The microstructure of the curd (Figure 4) showed that the casein strands were thin, granular strings and 


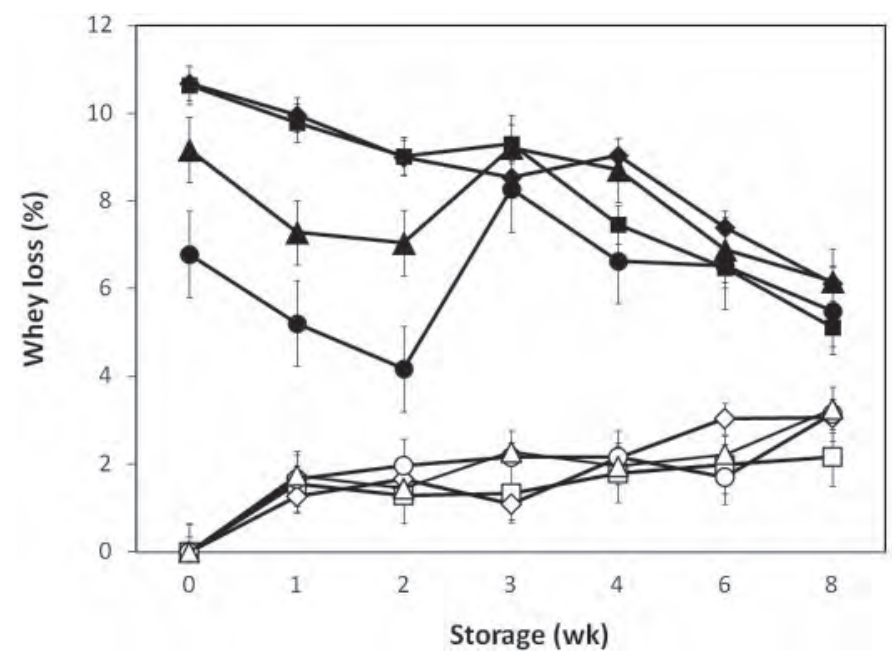

Figure 3. Amount of whey lost from cheese matrix during storage at $4^{\circ} \mathrm{C}$, measured as free whey recovered from package (open symbols) and expressible serum or whey removed from cheese upon mild centrifugation (filled symbols). Milling treatments included no milling (control, $\mathbf{\square}, \square$ ), passed through the milling unit without a blade (coarse, -), milled using a blade with large holes (medium, $\bullet, \bigcirc)$, or milled using a blade with small holes (fine, $\boldsymbol{\Lambda}, \Delta$ ). Error bars represent SD.

had numerous small, round, open areas where the lipid droplets had been and plenty of voids or irregular open areas between the protein strands. This would hold the free and expressible whey within the cheese. At wk 1, the micelles that made up the protein matrix had crisp edges. By wk 8, the edges were not quite so crisp and the protein strands had thickened slightly. The microstructure was similar to that of other high-moisture fresh Hispanic-style cheeses (Tunick et al., 2008; Guo et al., 2011). The compaction and fusion of the protein matrix so typical of the semi-hard and hard-pressed cheeses made with starter cultures were not present (Tunick et al., 1993).

Color and Meltability. Neither the milling steps nor the length of storage altered the color or nonmelt properties of this cheese (data not included). The $\mathrm{L}^{*}$ values, which represent the whiteness of the samples, were $92.1 \pm 0.3$ before heating, $72.9 \pm 5.0$ after heating at $130^{\circ} \mathrm{C}$ for $30 \mathrm{~min}$ (baking temperature), and $83.5 \pm$ 6.6 after heating at $232^{\circ} \mathrm{C}$ for $5 \mathrm{~min}$ (broiling temperature); values remained within these ranges over the 8 wk of the study. The total color change for QF was 21.6 \pm 2.2 when baked and $7.37 \pm 2.50$ when broiled. The trends observed after heating were similar to those reported by others (Guo et al., 2011; Tunick et al., 2012). Queso Fresco is noted for being a nonmelting cheese, which should soften when heated but not collapse and flow (Van Hekken and Farkye, 2003). The QF was made with milk with $3.5 \%$ fat that had been homogenized before cheesemaking. Homogenization reduces the size of the fat droplet and embeds $\mathrm{CN}$ micelles around the surface of the droplet, thus restricting the ability of the cheese matrix to collapse and flow when heated (Tunick et al., 1993). Homogenized milk was used specifically in making QF to ensure the nonmelt property of the cheese.

\section{Rheological Properties}

Texture Profile Analysis. Texture properties collected from the time-force curves (Table 2) showed that the $\mathrm{QF}$ was a soft cheese with hardness values of less than $20 \mathrm{~N}$ that decreased $(P<0.05)$ as the milling became finer, yet did not change significantly as the cheese aged. Initial cohesiveness and springiness values were similar for the nonmilled, coarsely milled, and medium-milled QF, but the finely milled QF was lower $(P<0.05)$ than the nonmilled and coarsely milled QF for cohesiveness and was lower $(P<0.05)$ than the coarsely milled $\mathrm{QF}$ for springiness. The initial chewiness of $\mathrm{QF}$ decreased $(P<0.05)$ as the milling became finer and over $8 \mathrm{wk}$ of storage for the nonmilled and coarsely milled samples; the medium-milled and finely milled QF remained stable. The nonmilled (control) QF had the strongest matrix with the highest values for hardness, chewiness, springiness, and cohesiveness. Of the milled samples, the finely milled cheese had the lowest values.

Torsion. Rheological properties collected at the point of fracture also supported the fact that the QF was a weak-bodied cheese (Table 2). Shear stress values at the point of fracture were less than $13 \mathrm{kPa}$, with the nonmilled QF having the highest stress values at fracture; the other treatments showed variable results. At wk 1, all cheeses fractured at a low strain, below 0.76 , which is a good indication of crumbliness. The milled QF increased $(P<0.05)$ in strain tolerance the longer they were stored. Rigidity at the point of fracture (stress/strain) showed that the nonmilled cheeses were more rigid $(P<0.05)$ than the milled cheeses, which were similar to each other.

Viscoelastic Properties. The viscoelastic properties, which relate to the strength of the component interactions or bonds within the matrix, also supported the fact that the QF was a soft cheese with a weak microstructure (Table 2). All QF had similar values for the elastic modulus, which reflects the ability of the sample to stretch and flex, at wk 1, whereas the values for the nonmilled and coarsely milled QF increased $(P$ $<0.05)$ over the 8 wk of the study, and the mediummilled and finely milled QF remained the same. The viscous modulus, which represents the ability of the sample components to flow within the matrix, was similar for all of the treatments at wk 1 and remained 

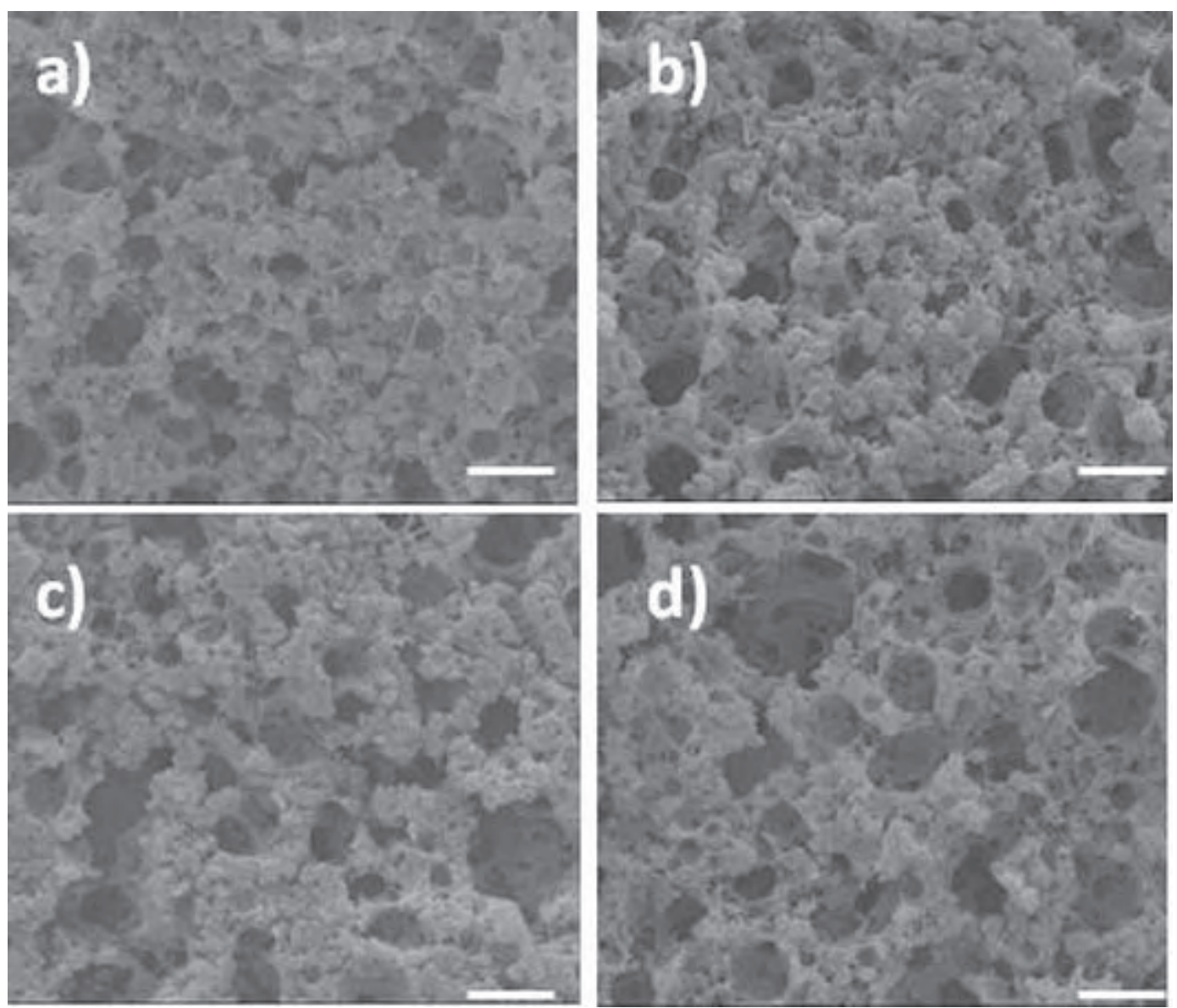

Figure 4. Scanning electron micrographs representative of the microstructure of Queso Fresco: a) no milling at wk 1, b) fine milling at wk 1, c) no milling at wk 8, and d) fine milling at wk 8. Bar represents $2.0 \mu \mathrm{m}$.

the same throughout the study, except for an increase $(P<0.05)$ noted for the nonmilled QF.

Although the other QF studies may not have conducted the same rheological tests, our results agree with their findings that $\mathrm{QF}$ has a soft fragile matrix that does not hold together well, or crumbles easily. Hwang and Gunasekaran (2001) reported that commercial US-made QF with moisture contents ranging from 46 to $57.1 \%$ had hardness values ranging from 7.4 to $20.5 \mathrm{~N}$, cohesiveness values from 0.63 to 0.83 , shear fracture stress values from 7.1 to $29.2 \mathrm{kPa}$, and shear fracture strain values from 0.61 to 1.23 . The one brand that was made from unhomogenized milk and did not have its curd broken before hooping had the highest values. Sandra et al. (2004) reported that the raw milk QF had moisture levels similar to our QF but were considerably firmer and chewier in texture. Textural differences in the results between the 2 studies may have been because of the addition of a starter culture, light pressing of the $\mathrm{QF}$, and the maximum storage of only $8 \mathrm{~d}$ in the Sandra study. Results from our study were similar to those reported in tangential studies from our laboratory (Guo et al., 2011; Tunick et al., 2012).

Rheological data showed that the nonmilled samples were firmer than the cheeses that had been milled. Although many texture traits decreased as the milling broke the curd into smaller masses, other rheological properties were similar among the milling treatments. Because the rheological tests had very low values, a consumer difference test was conducted to determine whether untrained consumers could detect differences between the treatments.

\section{Sensory Evaluations}

Difference tests were conducted by in-house panelists; all ate cheese on a regular basis. Panelists consisted of 11 males and 12 females, of which 3 were under the age of $30 \mathrm{yr}, 7$ were between 31 and $50 \mathrm{yr}$, and 13 were more than $50 \mathrm{yr}$ of age. Results from the triangle tests indicated that panelists correctly identified the finely milled QF from the nonmilled control $(P<0.01)$ and 


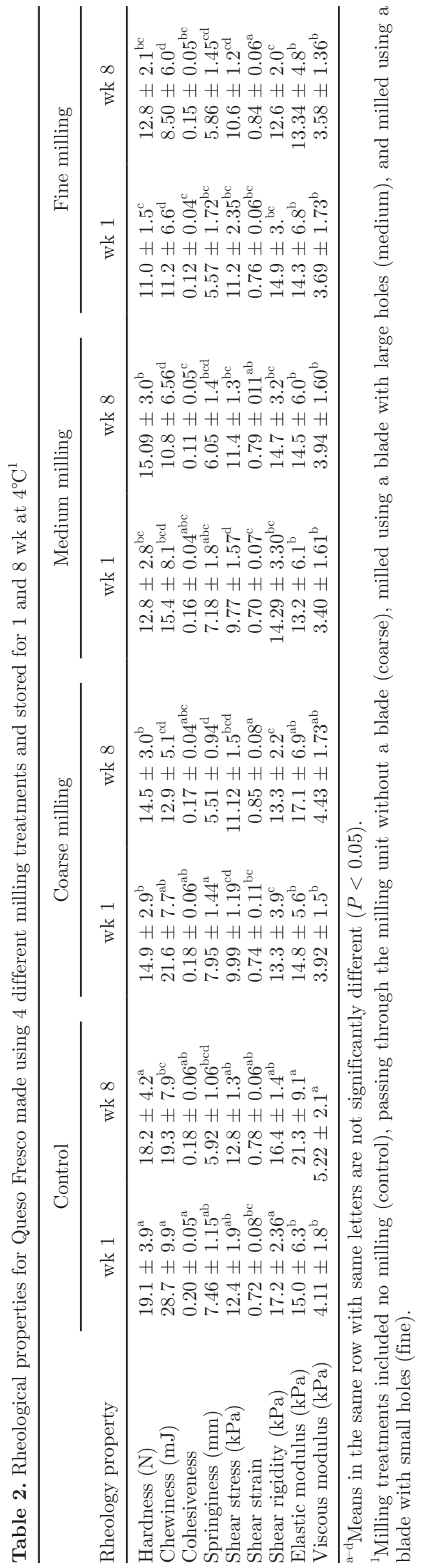

the finely and medium-milled QF $(P<0.05)$. Panelists could not tell the difference between the nonmilled control, coarsely milled, or medium-milled samples $(P$ $>0.05)$.

\section{Microbiological Properties}

Curds underwent 4 different milling treatments in an attempt to create different matrices within the $\mathrm{QF}$, and then freshly cut surfaces of the cheese were inoculated with $L m$ to determine any differences in the growth of the $L m$. Results showed that $L m$ increased almost $6 \log _{10} \mathrm{cfu} / \mathrm{g}$ over $21 \mathrm{~d}$ of storage at $4^{\circ} \mathrm{C}$ for all $\mathrm{QF}$ (Figure 5). The growth of the $L m$ was the same for the nonmilled and milled QF, indicating that the texture of the cheese did not impede $L m$ growth and would not be a consideration in determining whether the milling step could be omitted. In a tangential study (Leggett et al., 2012), QF was shown to be an excellent growth medium for $L m$, reaching 7 to $8 \log _{10} \mathrm{cfu} / \mathrm{g}$ within 11 $\mathrm{d}$ when stored at $10^{\circ} \mathrm{C}$ and within $27 \mathrm{~d}$ when stored at $4^{\circ} \mathrm{C}$. The growth patterns were similar whether the $\mathrm{Lm}$ inocula were added to the curd before packing in the cheese molds or spread on the surface of the cheese slice. Postpasteurization bacterial contamination, especially by $L m$, is the major problem in fresh, highmoisture, high-pH Hispanic-style cheeses (Linnan et al., 1988; Johnson et al., 1990; Farber and Peterkin, 1991; Genigeorgis et al., 1991; CDC, 2001; Mac Donald et al., 2005). Good plant sanitation practices, especially for

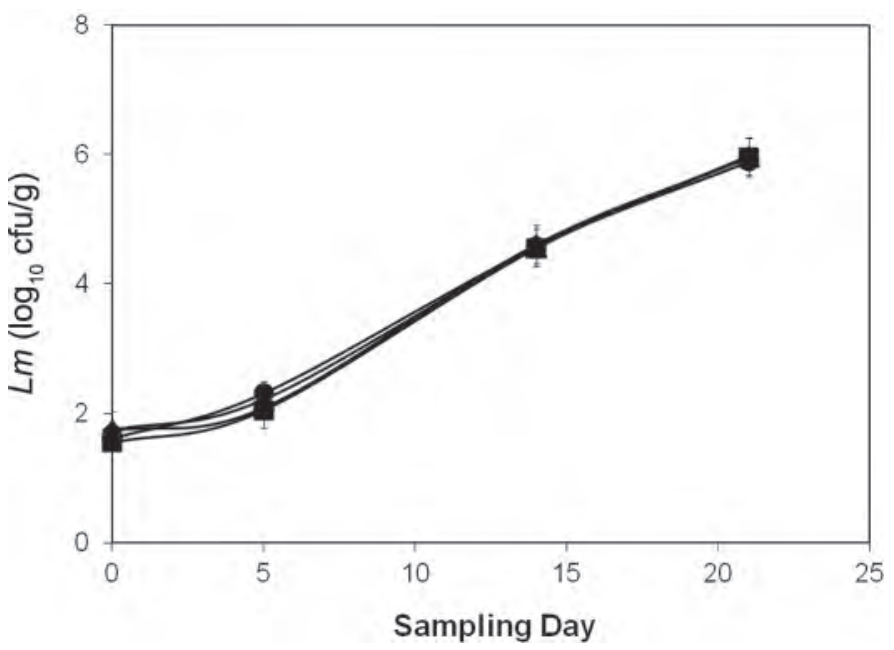

Figure 5. Growth of Listeria monocytogenes on Queso Fresco manufactured using different curd milling treatments and stored at $4^{\circ} \mathrm{C}$ for up to $21 \mathrm{~d}$. Milling treatments included no milling (control, $\mathbf{0}$ ), passed through the milling unit without a blade (coarse, $\bullet$ ), milled using a blade with large holes (medium, $\bullet$ ), or milled using a blade with small holes (fine, $\mathbf{\Delta}$ ). Error bars represent SD. 
potential high-risk steps such as milling equipment, are essential to ensure the food safety of QF.

\section{CONCLUSIONS}

Milling the curd before hooping disrupted the protein matrix and resulted in QF that was softer than the nonmilled control. Consumers could differentiate between the finely milled QF and other treatments. Although the medium- and finely milled cheeses had lower levels of expressible serum in the first $2 \mathrm{wk}$ of the study, by wk 8 , the nonmilled control tended to have the least amount of accumulated free whey in the package. Cheese manufacturers can use this information to produce a $\mathrm{QF}$ that meets the demands of their customers.

\section{ACKNOWLEDGMENTS}

Authors thank ARS researchers James Shieh, Brien Sullivan, Danielle Tilman, and Doug Soroka for their contribution to this research and to John Luchansky for the rif-resistant $L m$ used in this study. Research was partially funded by Dairy Management Inc. (administered by the Dairy Research Institute, Rosemont, IL).

\section{REFERENCES}

AOAC International. 2000. Official Methods of Analysis of AOAC International. 17th ed. AOAC Int., Arlington, VA.

CDC (Centers for Disease Control and Prevention). 2001. Outbreak of listeriosis associated homemade Mexican-style cheese-North Carolina, October 2000-January 2001. Morb. Mortal. Wkly. Rep. 50:560-562.

CFR (Code of Federal Regulations). 2011. Title 21, Sec. 1240.61. Mandatory pasteurization for all milk and milk products in final package form intended for direct human consumption. Accessed Feb. 29, 2012. http://www.accessdata.fda.gov/scripts/cdrh/cfdocs/cfcfr/CFRSearch.cfm?fr=1240.61.

Clark, S., W. Warner, and L. Luedecke. 2001. Acceptability of Queso Fresco cheese by traditional and nontraditional consumers. Food Sci. Technol. Int. 7:165-170.

Escobar, D., S. Clark, V. Ganesan, L. Repiso, J. Waller, and F. Harte. 2011. High pressure homogenization of raw and pasteurized milk modifies the yield, composition, and texture of queso fresco cheese. J. Dairy Sci. 94:1201-1210.

Farber, J. M., and P. I. Peterkin. 1991. Listeria monocytogenes, a foodborne pathogen. Microbiol. Rev. 55:476-511.

Genigeorgis, C., J. H. Toledo, and F. J. Garayzabal. 1991. Selected microbiological and chemical characteristics of illegally produced and marketed soft Hispanic-style cheeses in California. J. Food Prot. 54:598-601.

Guo, L., D. L. Van Hekken, P. M. Tomasula, J. Shieh, and M. T. Tunick. 2011. Effect of salt on the chemical, functional, and rheological properties of Queso Fresco during storage. Int. Dairy J. 21:352-357.

Guo, L., D. L. Van Hekken, P. M. Tomasula, M. H. Tunick, and G. Huo. 2012. Effect of salt on microbiology and proteolysis of Queso Fresco cheese during storage. Milchwissenschaft 67:74-77.
Higuera-Ciapara, I. 1986. Small-scale cheesemaking of Latin American cheeses. Cheesemaker's J. 23:4-5.

Hunter, R. S. 1975. The Measurement of Appearance. John Wiley and Sons Inc., New York, NY.

Hwang, C. H., and S. Gunasekaran. 2001. Measuring crumbliness of some commercial Queso Fresco-type Latin American cheeses. Milchwissenschaft 56:446-450.

Johnson, E. A., J. H. Nelson, and M. Johnson. 1990. Microbiological safety of cheese made from heat-treated milk. Executive summary, Introduction and history. J. Food Prot. 53:441-452, 519-540.

Kosikowski, F. V., and V. V. Mistry. 1997. Cheese and Fermented Milk Foods. Vol. 2. Procedures and Analysis. 3rd ed. F. V. Kosikowski, LLC, Westport, CT.

Leggett, L. N., P. M. Tomasula, D. L. Van Hekken, A. C. S. PortoFett, B. Shoyer, J. A. Renye, J. B. Luchansky, and N. Farkye. 2012. Effect of storage at 4 and $10^{\circ} \mathrm{C}$ on the growth of Listeria monocytogenes in and on Queso Fresco. J. Food Saf. 32:236-245.

Linnan, M. J., L. Mascola, X. D. Lou, V. Goulet, S. May, C. Salminen, D. W. Hird, M. L. Yonekura, P. Hayes, R. Weaver, A. Audurier, B. D. Plikaytis, S. L. Fannin, A. Kleks, and C. V. Broome. 1988. Epidemic listeriosis associated with Mexican-style cheese. N. Engl. J. Med. 319:823-828.

MacDonald, P. D. M., R. E. Whitwam, J. D. Boggs, J. N. MacCormack, K. L. Anderson, K. L. Reardon, J. R. Saah, L. M. Graves, S. B. Hunter, and J. Sobel. 2005. Outbreak of listeriosis among Mexican immigrants as a result of consumption of illicitly produced Mexican-style cheese. Clin. Infect. Dis. 40:677-682.

Meilgaard, M., G. V. Civille, and B. T. Carr. 1999. Overall difference tests. Pages.59-98 in Sensory Evaluation Techniques. 3rd ed. CRC Press, New York, NY.

NASS (National Agricultural Statistics Service). 2011. Dairy Products 2009 Summary. Accessed Jul. 8, 2011. http://usda.mannlib.cornell.edu/usda/current/DairProdSu/DairProdSu-04-29-2010.txt.

Olson, D. W., D. L. Van Hekken, M. H. Tunick, K. A. Soryal, and S. S. Zeng. 2007. Effects of aging on functional properties of caprine milk made into Cheddar- and Colby-like cheeses. Small Rumin. Res. 70:218-222.

Path, J. 1991. Hispanic cheeses: A promising new market for the specialty cheesemaker. UW Dairy Pipeline 3:1-4.

Sandra, S., M. A. Stanford, and L. Meunier Goddik. 2004. The use of high-pressure processing in the production of Queso Fresco cheese. J. Food Sci. 69:FEP153-FEP158.

Scott, R. 1986. Cheesemaking operations. Pages 186-212 in Cheesemaking Practice. 2nd ed. Elsevier Applied Science Publishers, London, UK.

Torres-Llanez, M. J., B. Vallejo-Cordoba, M. E. Diaz-Cinco, M. A. Mazorra-Manzano, and A. F. Gonzalez-Cordova. 2006. Characterization of the natural microflora of artisanal Mexican fresco cheese. Food Contr. 17:683-690.

Tunick, M. H., E. L. Malin, P. W. Smith, J. J. Shieh, B. C. Sullivan, K. L. Mackey, and V. H. Holsinger. 1993. Proteolysis and rheology of low fat and full fat Mozzarella cheeses prepared from homogenized milk. J. Dairy Sci. 76:3621-3628.

Tunick, M. H., D. L. Van Hekken, and P. H. Cooke. 2008. Rheology and microstructure of Queso Blanco as affected by pressing procedure and storage conditions. Milchwissenschaft 63:157-160.

Tunick, M. H., D. L. Van Hekken, S. K. Iandola, and P. M. Tomasula. 2012. Characterization of Queso Fresco during storage at 4 and $10^{\circ} \mathrm{C}$. J. Food Res. 1:308-319.

Van Hekken, D. L., and N. Farkye. 2003. Hispanic cheeses: The quest for Queso. Food Technol. 57:32-38.

Van Hekken, D. L., M. H. Tunick, P. M. Tomasula, F. J. Molina Corral, and A. A. Gardea. 2007. Mexican Queso Chihuahua: Rheology of fresh cheese. Int. J. Dairy Technol. 60:5-12.

Weigold, W. G. 1958. Development of a factory method for the manufacture of Queso del Pais. Milk Prod. J. 49:16-17. 